\title{
Sitaxsentan-induced acute severe hepatitis treated with glucocorticoid therapy
}

\author{
Marcus W Chin MBBS(Hons) FRACP1 , Robert D Levy MD FRCPC ${ }^{2}$, \\ Eric M Yoshida MD FRCPC ${ }^{3}$, Michael F Byrne MA MD(Canterb) MRCP FRCPC ${ }^{3}$
}

MW Chin, RD Levy, EM Yoshida, MF Byrne. Sitaxsentan-induced acute severe hepatitis treated with glucocorticoid therapy. Can Respir J 2012;19(1):e1-e2.

Endothelin receptor antagonists are commonly used in the treatment of pulmonary hypertension. Sitaxsentan, a selective endothelin A receptor blocker, induces a mild transaminitis in approximately $3 \%$ to $5 \%$ of patients, but rarely an acute severe hepatitis. A case involving a 61-yearold female with sitaxsentan-induced acute severe liver failure is presented. Depite withdrawal of therapy, her liver tests failed to improve. After six weeks of monitoring, the patient was administered high-dose corticosteroids, with a good clinical and biochemical response. While endothelin receptor antagonists are postulated to cause hepatitis by inhibition of a bile salt transporter pump, an immune-mediated or idiosyncratic mechanism should be considered.

Key Words: Endothelin receptor antagonists; Hepatits; Sitaxsentan

Cndothelin receptor antagonists (ETRAs) are oral agents used for Ethe treatment of pulmonary arterial hypertension. Of the endothelin receptor antagonists, bosentan, a nonselective endothelin-1 receptor antagonist, was initially approved for use in 2001/2002 based on two studies that showed improved exercise capacity and hemodynamic parameters, while delaying time to clinical worsening (1). Fourteen per cent of patients using bosentan in these studies developed elevation in serum aminotransferase levels of more than three times the upper limit of normal (1). Sitaxsentan is a newer ETRA agent with selective endothelin A receptor blockade, and reputed to cause significantly less drug-induced hepatitis (3\% to 5\%) (2). There are five reported cases of sitaxsentan induced severe hepatitis, of which two were fatal (3-5).

\section{CASE PRESENTATION}

The patient, a 61-year-old female with pulmonary arterial hypertension on a background of an atrial septal defect repair 15 years earlier, atrial flutter, atrioventricular node ablation and pacemaker insertion was commenced on sitaxsentan ( $100 \mathrm{mg} /$ day for 16 weeks). Her liver enzyme levels were near normal at baseline (alanine aminotransferase $24 \mathrm{U} / \mathrm{L}$ (normal $<50 \mathrm{U} / \mathrm{L}$ ), aspartate aminotransferase $28 \mathrm{U} / \mathrm{L}$ (normal $<35 \mathrm{U} / \mathrm{L}$ ), alkaline phosphatase $112 \mathrm{U} / \mathrm{L}$ (normal <120 U/L), bilirubin $11.6 \mu \mathrm{mol} / \mathrm{L}$ (normal $0 \mu \mathrm{mol} / \mathrm{L}$ to $18 \mu \mathrm{mol} / \mathrm{L}$ ), and she had no known history of liver disease. Concomitant medications included warfarin $2 \mathrm{mg}$ once/day, diltiazem $100 \mathrm{mg}$ four times/day, furosemide $20 \mathrm{mg}$ four times/day orally, vitamin $\mathrm{D}$ and calcium. Liver enzyme levels were checked on a regular basis. After eight weeks of therapy, her liver enzyme levels became abnormal. Due to a continued deterioration in liver enzymes, sitaxsentan was discontinued six weeks later.

Despite cessation of therapy, there was continued worsening of all liver parameters over the next six weeks, and the patient was admitted

\section{L'hépatite aiguë sévère induite par le sitaxsentan traitée par glucocorticoïdes}

Les antagonistes des récepteurs de l'endothéline sont souvent utilisés pour traiter l'hypertension pulmonaire. Le sitaxsentan, un antagoniste des récepteurs sélectifs de l'endothéline $\mathrm{A}$, induit une transaminite bénigne chez environ $3 \%$ à $5 \%$ des patients, mais rarement une hépatite aiguë sévère. Les auteurs présentent le cas d'une femme de 61 ans atteinte d'une insuffisance hépatique aiguë sévère induite par le sitaxsentan. Malgré l'arrêt du traitement, les tests hépatiques ne se sont pas améliorés. Au bout de six semaines de suivi, on a administré de fortes doses de corticoïdes à la patiente, qui a présenté une bonne réponse clinique et biochimique. On postule que les antagonistes des récepteurs de l'endothéline sont responsables de l'hépatite par inhibition d'une pompe d'exportation de sels biliaires, mais il faudrait envisager un mécanisme idiosyncrasique ou à médiation immune.

to hospital for monitoring and investigation. On examination, she was clearly jaundiced, but had no stigmata of chronic liver disease nor encephalopathy. Investigations performed included a normal abdominal ultrasound and autoimmune screen (antinuclear antibody, antineutrophil cytoplasmic antibody, antismooth muscle antibody, antiliver kidney microsomal antibody, antimitochondrial antibody), negative hepatitis A, B and C, and Epstein-Barr virus and cytomegalovirus serology, and negative toxicology screen. The patient underwent a liver biopsy, which revealed a mixed inflammatory infiltrate with piecemeal necrosis of hepatocytes, without evidence of Mallory's hyaline, alpha-1 antitrypsin bodies nor iron deposition.

With the clinical scenario and investigations suggesting druginduced hepatitis, and the bilirubin failing to improve despite cessation of sitaxsentan six weeks previously, the patient was commenced on high-dose corticosteroids, with good effect. Following four weeks of tapering oral corticosteroid therapy, her liver enzymes normalized (Figures 1 and 2).

\section{DISCUSSION}

The mechanism of ETRA-induced hepatitis is not clearly known. Bosentan-induced hepatitis is postulated to occur by inhibition of a bile-salt transporter pump (6). Sitaxsentan is also postulated to have a direct heptatotoxic effect on hepatocytes $(4,7)$. Ambrisentan, a newer ETRA, is not believed to have an effect on the bile-salt transporter pump, and remains an alternative therapy for patients intolerant to bosentan/sitaxsentan for reasons of hepatotoxicity (7).

The classical hallmarks of a direct hepatotoxin are that they are dose related, with rapid improvement of liver function on drug withdrawal. In our case, there was no resolution of jaundice despite a long observation period of six weeks until corticosteroids were administered.

${ }^{1}$ Faculty of Medicine and Dentistry, University of Western Australia, Australia; ${ }^{2}$ Division of Respiratory Medicine, Vancouver General Hospital,

Department of Medicine, University of British Columbia; ${ }^{3}$ Division of Gastroenterology, Vancouver General Hospital, Faculty of Medicine,

University of British Columbia, Vancouver, British Columbia

Correspondence: Dr Marcus Chin, University of Western Australia, 197 Wellington Street, Perth, Western Australia 6001, Australia.

Telephone 8-9224-2244, e-mail marcus.chin@health.wa.gov.au 


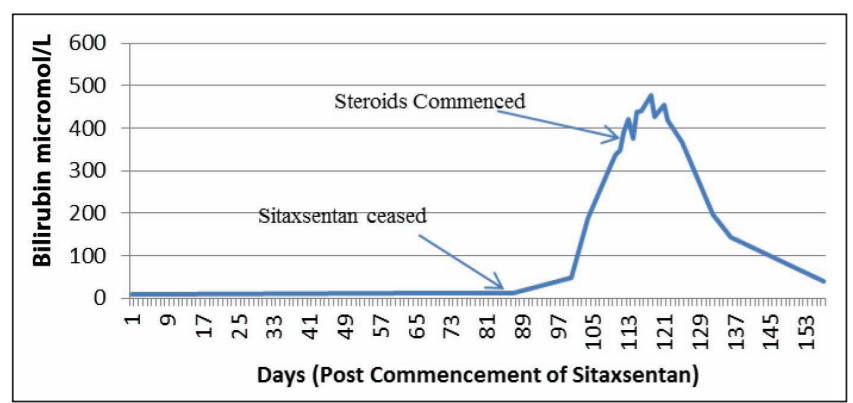

Figure 1) Bilirubin levels after commencement of sitaxsentan

Of the five published cases of sitaxsentan-induced hepatitis, one was treated with steroids after an observation period following cessation of therapy, and did not result in improvement of liver function (5). There was a rapid resolution of the hepatitis following steroid induction. Of the four other cases that were treated supportively after withdrawal of sitaxsentan, two died. While the delayed recovery may occur as a result of the nonlinear pharmacokinectics of sitaxsentan (4), an immune-mediated mechanism should be considered.

\section{REFERENCES}

1. Rubin LJ, Badesch DB, Barst RJ, et al. Bosentan therapy for pulmonary arterial hypertension. N Engl J Med 2002;21;346:896-903.

2. Barst RJ, Langleben D, Badesch D, et al. Treatment of pulmonary arterial hypertension with the selective endothelin-A receptor antagonist sitaxsentan. J Am Coll Cardiol 2006;16;47:2049-56.

3. Barst RJ, Rich S, Widlitz A, Horn EM, McLaughlin V, McFarlin J. Clinical efficacy of sitaxsentan, an endothelin-A receptor antagonist, in patients with pulmonary arterial hypertension: Open-label pilot study. Chest 2002 Jun;121:1860-8.

4. Lavelle A, Sugrue R, Lawler G, et al. Sitaxentan-induced hepatic failure in two patients with pulmonary arterial hypertension. Eur Respir J 2009;34:770-1.

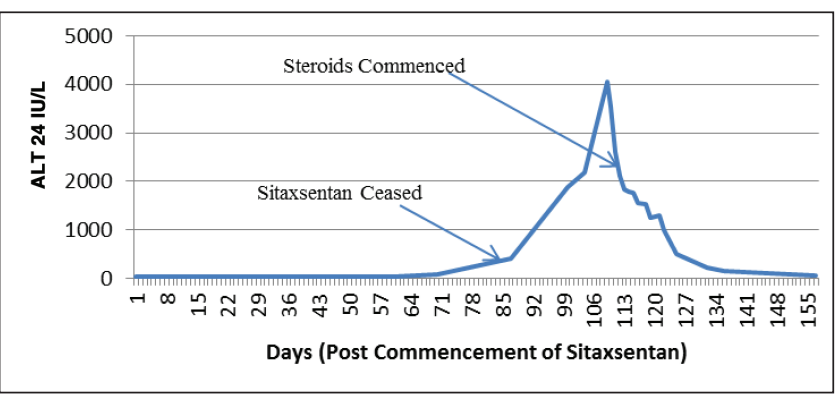

Figure 2) Alanine aminotransferase (ALT) levels after commencement of sitaxsentan therapy

\section{CONCLUSION}

Nonclinically significant elevation of transaminase levels with sitaxsentan therapy occur in 3\% to $5 \%$ of patients. To date, there are five cases of severe sitaxsentan-induced hepatitis in the literature. We presented a case of severe sitaxsentan-induced hepatitis that failed to resolve despite prolonged cessation of therapy, which required rescue glucocorticoid therapy. While it is currently postulated that sitaxsentan is directly hepatotoxic, an idiosyncratic or immune-mediated mechanism needs to be considered.

5. Hoeper MM, Olsson KM, Schneider A, Golpon H. Severe hepatitis associated with sitaxentan and response to glucocorticoid therapy. Eur Respir J 2009;33:1518-9.

6. Fattinger K, Funk C, Pantze M, et al. The endothelin antagonist bosentan inhibits the canalicular bile salt export pump: A potential mechanism for hepatic adverse reactions. Clin Pharmacol Ther 2001;69:223-31.

7. Hartman JC, Brouwer K, Mandagare A, Melvin L, Gorczynski R. Evaluation of the endothelin receptor antagonists ambrisentan, darusentan, bosentan, and stiaxsentan as substrates and inhibitors of hepatobiliary transporters in sandwich cultured human hepatocytes. Can J Physiol Pharmacol 2010;88:682-91. 


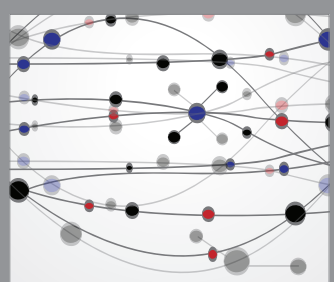

The Scientific World Journal
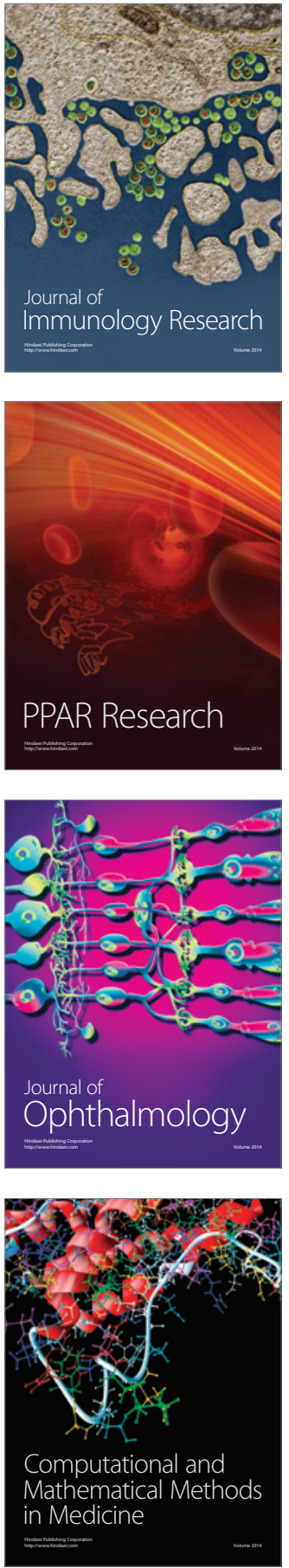

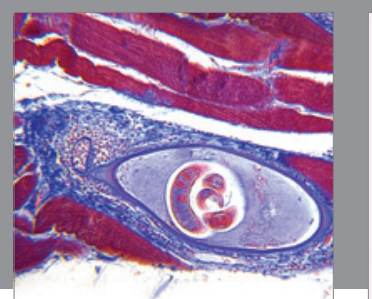

Gastroenterology Research and Practice

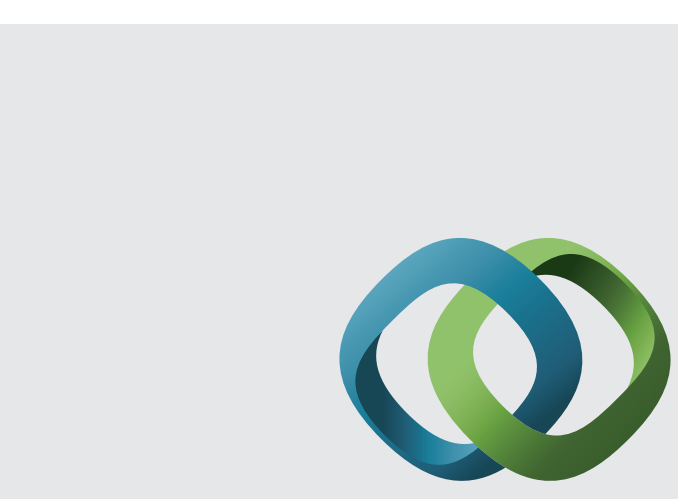

\section{Hindawi}

Submit your manuscripts at

http://www.hindawi.com
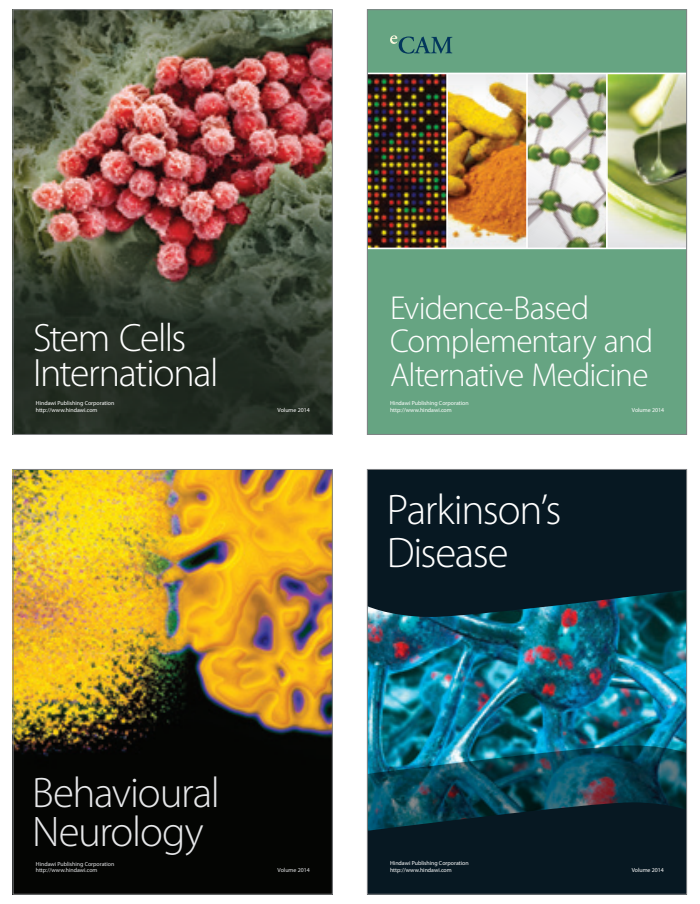
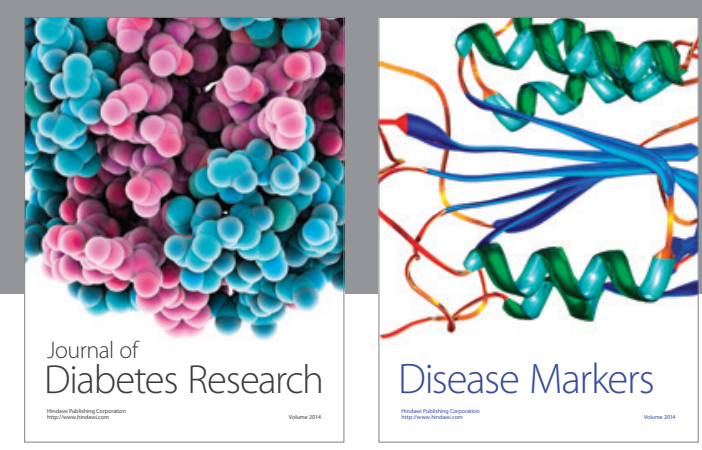

Disease Markers
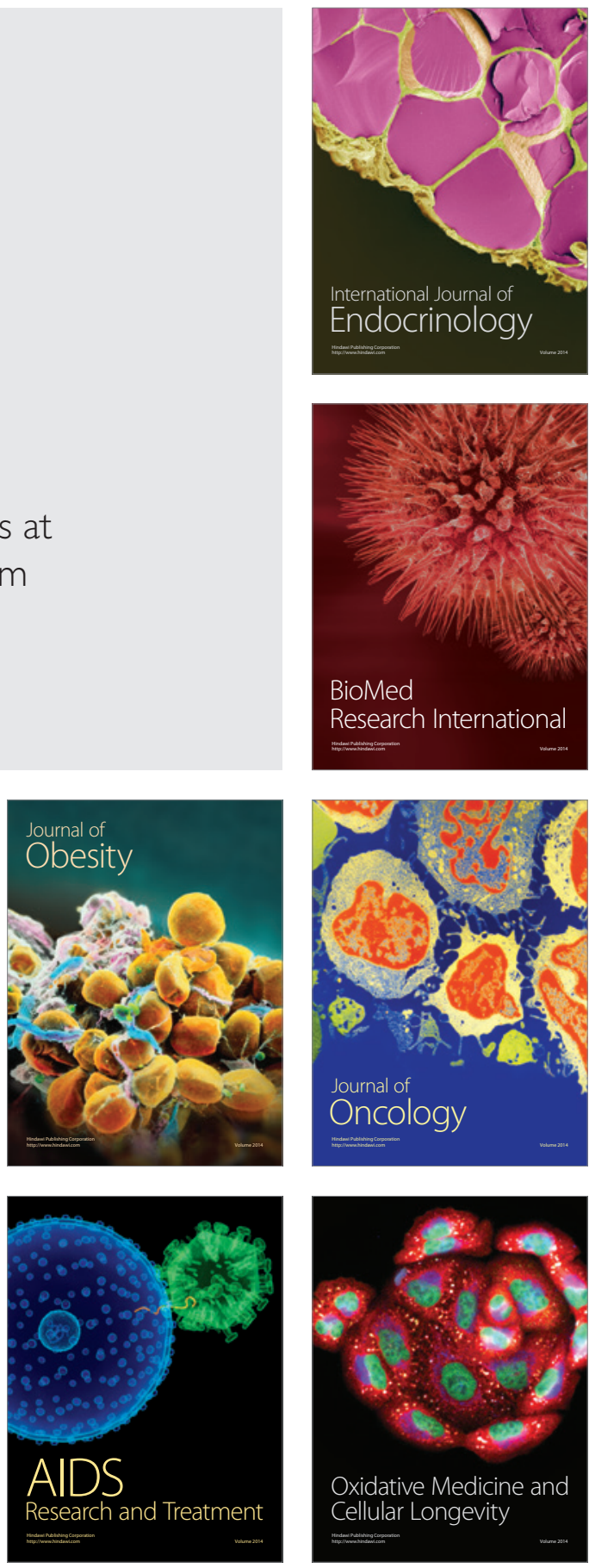